\title{
The rupture of the head of postmedial papillary muscle. Mechanical complications of myocardial infraction with normal angiographic image of coronary vessels.
}

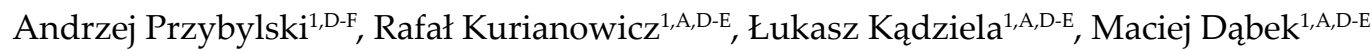 \\ A - Research concept and design, B - Collection and/or assembly of data, C - Data analysis and interpretation, \\ D - Writing the article, E - Critical revision of the article, F - Final approval of article \\ 1 Szpital Wojewódzki Nr 2 w Rzeszowie
}

Address for correspondence:

Andrzej Przybylski, Szpital Wojewódzki Nr 2 w Rzeszowie

email: a_przybylski-65@wp.pl

Rafał Kurianowicz, Szpital Wojewódzki Nr 2 w Rzeszowie

email: rkurianowicz@neostrada.pl

Łukasz Kądziela, Szpital Wojewódzki Nr 2 w Rzeszowie

email: lukaszkadziela@op.pl

Maciej Dąbek, Szpital Wojewódzki Nr 2 w Rzeszowie

email: maciek080@op.pl

Received: 23.12.2016

Revised: 30.12 .2016

Accepted: 31.12.2016

\begin{abstract}
Myocardial infarction with non-obstructive coronary arteries (MINOCA) is usually mild in course without any life-threatening complications.

This paper presents an atypical case of a 74-year- old patient with myocardial infarction who despite a normal an-
\end{abstract}

giography image suffered from complete tear of the head of the posteromedial papillary muscle followed by acute cardiac failure and cardiogenic shock.

\section{Key words:}

myocardial infarction, MINOCA, the rapture of the head of postmedial papillary muscle, mechanical complications of myocardial infarction, acute mitral regurge.

\section{Case study}

A 74-year- old female patient was treated for arterial hypertension, adult-onset diabetes, and paroxysmal atrial fibrillation. After implanting a dual-chamber cardiac pacemaker, as a result of second degree atrioventricular block, she was admitted to the Cardiology Ward with expanded pulmonary edema and low arterial blood pressure. Five days earlier the patient had reported coronary pain in the chest.

Following admission the patient's condition was generally severe with dyspnea at rest, which required passive oxygen therapy, but without chest pain.

Physical examination showed: arterial blood pressure of $90 / 60 \mathrm{~mm} / \mathrm{Hg}$ (in spite of using pressor amines), normal heart rate (60/min), auscultatory loud systolic murmur above the he- art apex radiating to the left axillary fossa and scapula, features characteristic for pulmonary congestion (class IV according to Killip and Kimball), blood oxygen saturation $79 \%$, mild swelling of lower legs, normal body temperature. Laboratory investigation indicated highly elevated levels of troponin T, N-terminal- pro B type natriuretic peptide (NT-proBNP) and $C$ reactive protein (CRP). Then, the electrocardiogram showed atrial fibrillation, and left bundle branch block with periodic and effective ventricular pacing. The indicative bedside transthoracic echocardiogram (TTE) presented lowered systolic function of the left ventricle muscle (EF about $40 \%$ ) with hypokinesis of the inferolateral, inferior, and lateral walls, as well as presence of hemodynamically significant mitral regurgitation due to prolapse of the posterior valve leaflet. As a matter of urgency, the diagnostics were extended to transe- 


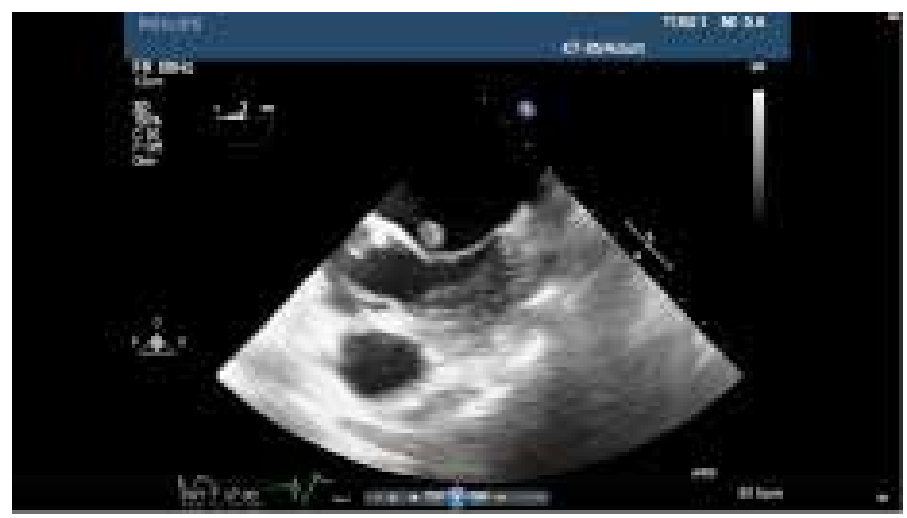

Figure 1 Mid esophageal modified view.

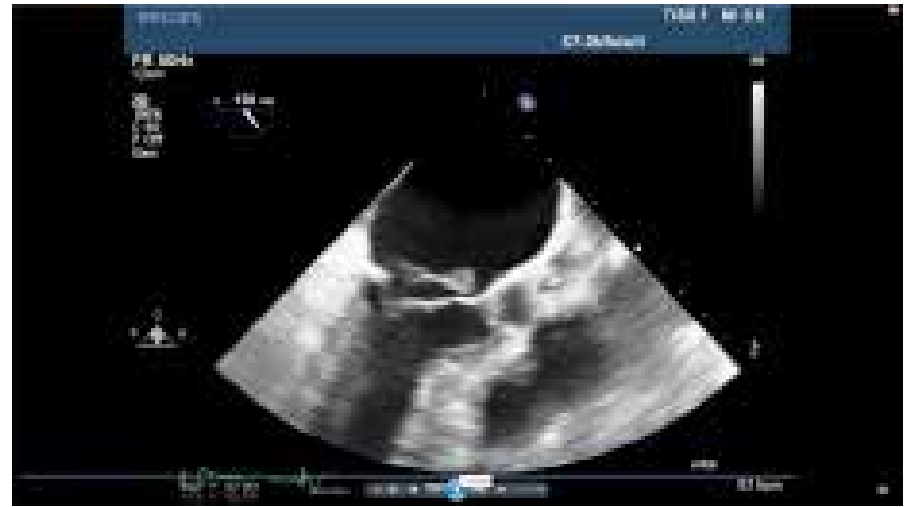

Figure 2 Mid esophageal long axis view.

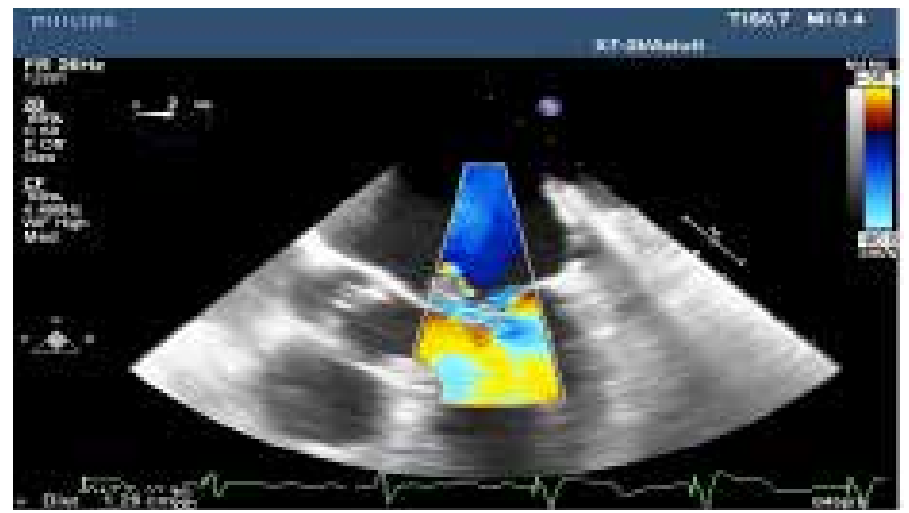

Figure 3 Mid esophageal modified view, with color Doppler.

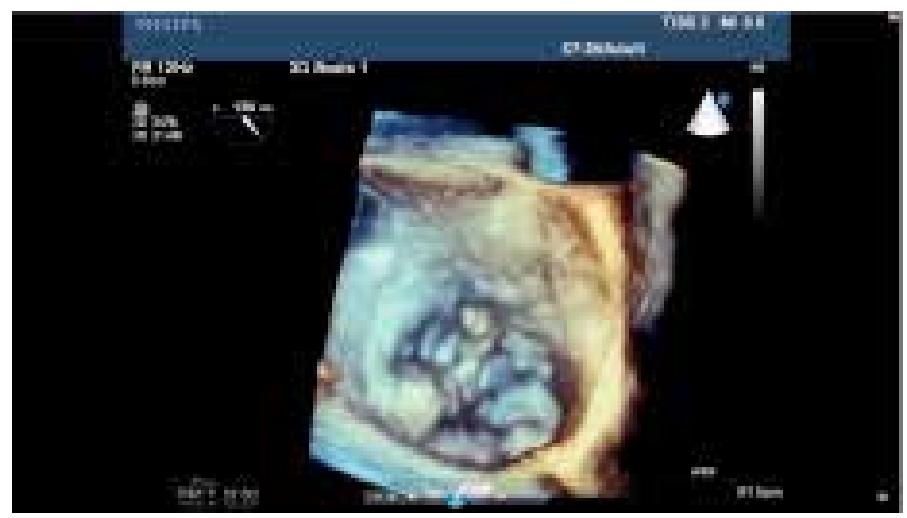

Figure 4 Mitral valve view from LA side in 3D projection.

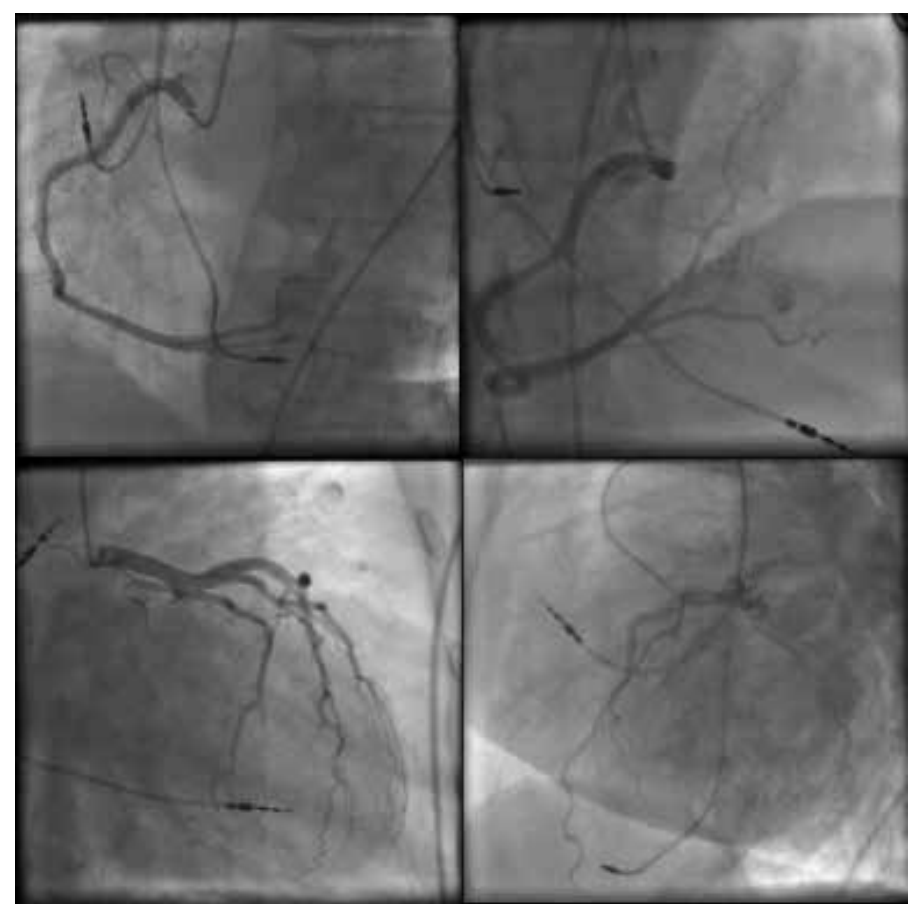

Figure Coronary angiography.

sophageal echocardiogram (TEE), which confirmed prolapse of a flail lateral mitral valve cusp with part of the head of the papillary muscle, attached with chordae tendineae, and with no additional structures which may have suggested infective endocarditis ${ }^{[2]}$.

The patient requireds intubation and mechanical ventilation with the help of a respirator. Coronary angiography detected no abnormality in coronary arteries. An intra-aortic balloon pump was introduced using the one-step method.

Next, after the cardiosurgical consultation the patient was immediately transferred to the local Cardiosurgical Clinic, where mitral valve replacement was successfully performed (Perimount Magna Mitral Ease [MVR] 29 mm - biological valve). As a result of lack of vegetation in the valve and subvalvular apparatus site, the necrotic area of the head of the postmedial papillary muscle was stated diagnosed intraoperatively. As the image of coronary vessels presented no abnormality, the blood culture and a part of papillary muscle were sampled in order to conduct histopathology. The results ultimately excluded infective endocarditis. During further hospitalization, the patient was gradually rehabilitated, and on the 12th day after the surgery she was transferred to the Cardiological Rehabilitation Department.

\section{Discussion}

The percentage of patients hospitalized as a result of myocardial infarction who on coronarography were not observed to have significant stenosis $(>50 \%)$ was respectively $7-23 \%$ of women and $6-12 \%$ of men. The pathomechanism of this disorder is not entirely clear, and some of its potential causes are: a coronary vessel spasm, spontaneous lysis of a clot, myocarditis, and coronary microvasculature spasm 
Table 1. Causes of MINOCA.

Mechanism

Coronary artery embolization

Myocarditis

\begin{abstract}
Coronary
microvasculature

spasm
\end{abstract}

\section{Coronary arteries \\ atherosclerotic \\ with positive \\ remodeling}

\author{
Takotsubo \\ cardiomyopathy
}

Endothelial dysfunction

thrombus, gas, fat, septic, cellular embolism

Adenovirus, parvovirus B19, Coxsackie, virus HHV-6

Endothelial dysfunction, hyperreactivity of coronary arterial smooth muscle, hyperreactivity of the parasympathetic nervous system

Growing atheroma
IVUS, OCT

angioCT, coronary angiography

MRI, SPECT

Acetylcholine or ergometrine test

$$
\begin{aligned}
& \text { measurements } \\
& \text { CFR, PET }
\end{aligned}
$$

Invasive

Contrast

echocardiography

with adenosine

administration,

MRI
Pharmacological treatment (CCBs, nitrates, Rho kinase inhibitors)

Pharmacological treatment (â-blockers, nitrates, CCBs), treatment of concomitant diseases (HA, DM-2, hyperlipemia)

Pharmacological treatment lantiplatelet therapy, statins)

\author{
Cardiac failure \\ treatment
}

(cardiac syndrome $\mathrm{X}$ ). Patients suffering from this disorder can be characterized by the following features: female gender, young age, lack of diseases predisposing to coronary disease development (arterial hypertension, adult-onset diabetes, hypercholesterolemia, obesity), and lack of family history. The prognosis in the case of MINOCA is usually good; rarely there is a possibility of cardiac failure, dangerous ventricular arrhythmias, mechanical complications, or death ${ }^{[1,3,6]}$.

One of the most common complications of myocardial infarction is the rupture of the head of the papillary muscle, which leads to acute mitral regurgitation. It occurs in about $1 \%$ of patients mostly on the 2nd to 7th day of infarction, usually on the inferior wall, among elderly women with single-vessel coronary disease suffering from diabetes. Preponderantly the posteromedial papillary muscle becomes damaged (6-12 times more often); unlike the anterolateral one, it is vascularised only in one coronary artery (a branch of the posterior descending right coronary artery in $95 \%$ of cases, or more rarely the third marginal artery branching off from the circumflex artery $)^{[4,5,8]}$. The basic treatment in acute mitral regurgitation caused by ischemic papillary muscle rupture is surgery. The aim of the pharmacological treatment is to stabilize and prepare the patient for the procedure. It mainly lowers the afterload and in consequence it reduces mitral reversal of blood flow. In order to achieve that, vasodilators (e.g. glycerol trinitrate, sodium nitroprusside) and loop diuretics are used. The therapy is limited by coexisting low blood pressure; therefore, introducing inotropic drugs (dopamine, noradrenaline) and mechanical support for the left ventricle (intra-aortic balloon pump or the Impella device) are crucial ${ }^{[7,11]}$. The surgical treatment is mainly based on replacing the mitral valve with a mechanical prosthesis. An attempt to repair a dysfunctional valve is rare, as it is difficult to work in the necrotic area ${ }^{[9,10]}$. The key is to 
diagnose the condition correctly, as in case of lack of treatment in patients suffering from it the mortality reaches $100 \%$.

\section{Summary}

The prognosis of myocardial infarction with no significant changes in coronary arteries is usually good, and life-threatening complications are unlikely to occur. However, myocardial necrosis may cause mechanical damage to the myocardium even when the coronary vessels are unobstructed. The pathomechanism of cardiac infarction in the case described above is not entirely clear. The most probable cause, due to the history of atrial fibrillation, is an embolism which lysed spontaneously. Extending the diagnostics (with OCT, CFR, IVUS, MRI) during hospitalization in order to establish MINOCA etymology was not possible because of the patient's general condition, and some additional tests (PET, SPECT) are not available in the hospital. If there is no possibility to stabilize the patient pharmacologically, the intra-aortic balloon pump (IABP) and a respirator are effective temporary procedures which help a patient to receive proper causal treatment. In the available literature there is no description of mechanical complications in this type of acute coronary syndrome.

\section{REFERENCES}

1. Niccoli G, Scalone G, Filippo Crea F. Acute myocardial infarction with no obstructive coronary atherosclerosis: mechanisms and management. European Heart Journal (2015) 36, 475-481. doi: 10.1093/eurheartj/ehu469.

2. Michałek P, Hoffman P. Częściowe pęknięcie mięśnia brodawkowatego w ostrym zawale mięśnia sercowego - rozpoznanie przy użyciu echokardiografii przezprzełykowej. Kardiol Pol 2006; 64: 637-640

3. Grodzinsky A, Arnold SV, Gosch K et al. Angina frequency after acute myocardial infarction in patients without obstructive coronary artery disease. European Heart Journal - Quality of Care and Clinical Outcomes. doi.org/10.1093/ehjqcco/qcv014

4. Fradley MG, Picard MH. Rupture of the posteromedial papillary muscle leading to partial flail of the anterior mitral leaflet. Circulation. 2011 Mar 8;123(9):1044-5. doi: 10.1161/CIRCULATIONAHA.110.984724.

5. Suarez K, Slicker K, Torres V. Diagnosis and management of papillary muscle rupture complicating acute myocardial infarction: a case report and review of the literature. Archives of Cardiovascular Imaging. 2015 August; 3(3): e30490. doi: 10.5812/acvi.30490

6. Reynolds HR. Myocardial infarction without obstructive coronary artery disease. Curr Opin Cariol. 2012 Nov;27(6):655-60. doi: 10.1097/HCO.0b013e3283583247.

7. Dalak F, Albardie A, Almutairi F et al. Anterolateral papillary muscle rupture caused by myocardial infarction. International Cardiovascular Forum Journal 3 (2015). doi: http://dx.doi.org/10.17987/icfj.v3i0.96
8. Jayawardena S, Renteria AS, Burzyantseva O et al. Anterolateral papillary muscle rupture caused by myocardial infarction: a case report. Cases J. 2008 Sep 20;1(1):172. doi: 10.1186/1757-1626-1-172.

9. Hansen AJ, Sorrell VL, Cooper AD et al. Postpartum rupture of the posteromedial papillary muscle. Journal of Cardiac Surgery February 2012. doi:10.1111/j.15408191.2011.01369.x

10. Jouan J, Tapia $M$, Cook RC et al. Ischemic mitral valve prolapse: mechanisms and implications for valve repair. Eur J Cardiothorac surg. 2004;26:1112-1117. doi: 10.1016/j.ejcts.2004.07.04.

11. Braunwald E, Bonow RO, Zipes PD et al. BRAUNWALD CHOROBY SERCA TOM 3. Edra Urban \& Partner. Wrocław 2007 wyd 1. 